\title{
Immunomodulatory and Antiangiogenic Mechanisms of Polymolecular Botanical Drug Extract C5OSEW5050ESA OS Derived from Orthosiphon stamineus
}

Fouad Saleih R. Al-Suede ${ }^{1 *}$, Mohamed B. Khadeer Ahamed ${ }^{1}$, Aman S. Abdul Majid $^{2}$, Sultan Ayesh Mohammed Saghir ${ }^{3}$, Chern E. Oon ${ }^{4}$, Amin Malik Shah Abdul Majid ${ }^{1,5^{*}}$

\begin{abstract}
Nuvastatic $^{\mathrm{TM}}$ is a polymolecular botanical drug formulation containing a proprietary extract of a selected cultivar of Orthosiphon stamineus (OS) code name, C5OSEW5050ESA OS. The anti-angiogenic activity of C5OSEW5050ESA OS was explored by evaluating its activity towards a variety of angiogenesis modulators in vitro and in vivo. Multiplex immunoassays reveals that C5OSEW5050ESA OS inhibits Vascular Endothelial Growth factor (VEGF), Epidermal Growth Factor (EGF), Fibroblast Growth Factor (FGF), Interleukin 2 ( IL-2) \& Interleukin 7 (IL-7), Nerve Growth Factor $\beta$ (NGF- $\beta$ ), Transforming Growth Factor $-\alpha$ (TGF- $\alpha$ ) and Tumor Necrosis Factor- $\beta$ (TNF- $\beta$ ). C5OSEW5050ESA OS also caused significant upregulation of interferon $\alpha$ (IFN- $\alpha$ ), interferon $\beta$ (IFN- $\beta$ ), interferon $\gamma$ (IFN- $\gamma$ ) and Granulocytemacrophage colony-stimulating factor (GM-CSF). C5OSEW5050ESA OS was found to inhibit endothelial cell proliferation and migration (92.6\%) and disrupts the tube assembly (98.26\%) for new blood vessel formation. The compound also inhibits neovascularisation in isolated rat aortic ring tissues (IC50 $18.2 \pm 2 \mu \mathrm{g} / \mathrm{mL}$ ) and in chick chorioallantoic membrane assays (CAM) by $82.7 \%$. In vivo matrigel plug assay treated with C5OSEW5050ESA OS
\end{abstract}

Significance | C5OSEW5050ESA OS strongly curbs variety of angiogenesis modulators in vitro, ex vivo and in vivo.

*Correspondence: $\quad$ Amin Malik Shah Abdul Majid, EMAN Biodiscoveries Sdn. Bhd., A1-4, Halal Park, 08000 Sungai Petani, Kedah, Malaysia. Email: aminmalikshah@gmail.com

Editor Fazlul Huq, Editor-in-Chief at Journal of Angiotherapy. And accepted by the Editorial Board March 13, 2021 (received for review January 19, 2021) shows inhibition of neovascularisation by $91.4 \pm 3 \%$. In conclusion, the study reveals that C5OSEW5050ESA OS has strong anti-angiogenic and immunomodulatory properties which may have significant clinical benefits in cancer therapy.

Key Words: Nuvastatic, C5OSEW5050ESA OS, Orthosiphon stamineus, antiangiogenic, immunomudolutary; Matrigel plug, Chick Chorioallantoic Membrane VEGF, EGF, FGF, GM-CSF, IL-1, IL-7, IFNs and TNF- $\beta$.

\section{Introduction}

Orthosiphon stamineus is a medicinal herb that is widely found in Malaysia and South East Asia. It has been used to treat various ailments (Aisha et al., 2014). The wide-spread traditional uses of this plant encourage many researchers to investigate the potential pharmacological properties of the plant. Various extracts and isolated compounds of $O$. stamineus exhibited useful pharmacological proprieties such as diuretic effect, anti-renal lithiasis, anti-oxidant, cytotoxic, anti-diabetic, anti-hypertensive, anti-inflammation, antibacterial, anti-obesity and hepatoprotective activities (Alshawsh et al., 2011; Mohamed et al., 2013; Al-Suede, et al., 2013). Prior study using 50\% ethanol extract O. stamineus (50\% EOS) showed potent anti-angiogenic in vitro and the phytochemical analysis of $50 \%$ EOS reveals the presence of rosmarinic acid (RA), eupatorin (EUP), sinensetin

\footnotetext{
Author Affiliation:

${ }^{1}$ EMAN Biodiscoveries Sdn. Bhd., A1-4, Halal Park, 08000 Sungai Petani, Kedah, Malaysia.

${ }^{2}$ Quest International University Perak, Malaysia

${ }^{3}$ Department of Medical Analysis, Princess Aisha Bint Al-Hussein Faculty of Nursing and Health Sciences, Al-Hussein Bin Talal University, Ma'an, Jordan

${ }^{4}$ Institute for Research in Molecular Medicine (INFORMM), Universiti Sains Malaysia, Penang 11800, Malaysia

${ }^{5}$ ACRF Department of Cancer Biology and Therapeutics, The John Curtin School of Medical Research, Australian National University, 131 Garran Rd., 2601 Acton, Australia.
}

Please cite this article:

Al-Suede, Fouad Saleih R.; Ahamed, Mohamed B. Khadeer; Abdul Majid, Aman S. Saghir, Sultan Ayesh Mohammed; Oon, Chern E; Abdul Maijd, Amin Malik Shah. (2021), Immunomodulatory and Antiangiogenic Mechanisms of Polymolecula Botanical Drug Extract C50SEW5050ESA OS Derived from Orthosiphon stamineus, Journal of Angiotheranv. 5(1). 194-206.

2207-8843/๑ 2019 ANGIOTHERAPY, a publication of Eman Research Ltd, Australia. This is an open access article under the CC BY-NC-ND license.

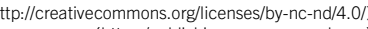
E194-E206 | ANGIOTHERAPY | Published online March 13, 2021 
(SIN), beutilinic acid (BA), 3'-hydroxy-5, 6, 7, 4'tetramethoxyflavone (TMF), oleanolic (OA) and ursolic acid (UA) (Al-Suede et al 2014b; Saidan et al.,2015; Akowuah et al., 2004; Hussain et al., 2012). The study also reveals that the EOS extract inhibits VEFGR phosphorylation and also suppressed VEGF expression and showed potent anti-tumor activity towards colorectal cancer in athymic mouse model (Ahamed et al. ,2012; Al-Suede et al. 2014a). However, greater detail concerning the mechanism of action is still unclear.

C5OSEW5050ESA OS commercially identified as Lanctos $75^{\mathrm{TM}}$ is a proprietary extract of a unique genotype of Orthosiphon stamineus laristatus leaves. Rosmarinic acid is the major active marker compound which constitute between 6-8\% w/w followed by eupatorin $0.6 \%$ and sinensetin $0.2 \% \mathrm{w} / \mathrm{w}$ and 3 '- hydroxy-5,6,7,4'tetramethoxyflavone (TMF) $0.05-0.1 \% \mathrm{w} / \mathrm{w}$. Nuvastatic ${ }^{\mathrm{TM}}$ is the effervescent formulation of C5OSEW5050ESA OS which has recently undergone a phase $2 / 3$ clinical studies for cancer fatigue in cancer patients with solid tumors stage I - IV receiving chemotherapy and/or radiotherapy (ClinicalTrials.gov Identifier: NCT04546607) In this work the antiangiogenic properties for the C5OSEW5050ESA OS extract was evaluated and the molecular mechanism pertaining its activity was investigated.

\section{Materials and Methods}

\section{Chemicals, cell culture and reagents}

Bovine serum albumin (Fraction V) was purchased from Sigma (Germany). Human cytokines assay kit was purchased from Procarta, USA, Phosphate buffered saline, trypsin, penicillin/streptomycin (PS), fibrinogen, aprotinin, thrombin, MTT reagent, suramin was purchased from Sigma, Germany. Matrigel matrix $(10 \mathrm{mg} / \mathrm{mL})$ was acquired from BD Bioscience, USA, anti-mouse podocalyxin Catalogue number AF1556 was purchased from (R\&D, USA). Alexa-Fluor 488 donkey anti-goat IgG, Catalogue number A11055,was obtained from life technology.USA HUVEC (ScienCell, USA) were maintained in endothelial cell medium (ECM) (ScienCell, USA) supplemented with $5 \%$ heat inactivated foetal bovine serum (HIFBS) and $1 \%$ PS. C5OSEW5050ESA OS extract standardised to $6 \%$ rosmarinic acid eupatorin $0.6 \%$, sinensetin $0.2 \% \mathrm{w} / \mathrm{w}$ and 3 '- hydroxy-5,6,7,4'tetramethoxyflavone (TMF) $0.05-0.1 \% \mathrm{w} / \mathrm{w}$ was sourced from NatureCeuticals Sdn. Bhd.

\section{High performance liquid chromatography (HPLC) analysis for C5OSEW5050ESA OS}

$50 \mathrm{mg}$ of C5OSEW5050ESA OS extract was separately dissolved in $25 \mathrm{ml}$ mixture of methanol and filtered through $0.45 \mu \mathrm{mfilter}$ (nylon membrane filter). Similarly all reference compounds (5 $\mathrm{mg}$ ) were dissolved in $5 \mathrm{ml}$ of methanol and then filtered. Determination of flavonoids (sinensetin, eupatorin, 3'-hydroxy-5,
6, 7, 4'-tetramethoxyflavone) and polyphenol (rosmarinic acid) present in C5OSEW5050ESA OS were carried out using reversephased HPLC equipped with a DAD detector. The entire marker compounds in C5OSEW5050ESA OS were separated within 10 min and absorbed at $320 \mathrm{~nm}$ (Saidan et al., 2015a).

\section{Ex vivo angiogenic study of C5OSEW5050ESA OS Extract on rat aortic ring assay. \\ Experimental Animals}

Eight to twelve weeks old Sprague Dawley male rats were obtained from the animal house facility of Eman Biodiscoveries and were kept for one week in transit animal unit at School of Pharmaceutical Sciences of Universiti Sains Malaysia (USM) to acclimatize with the new environment. The rats were kept in ventilated cages at 12 hour light cycle with food and water provided all the time. Experimental work was done following USM guidelines for animal ethics and the study was approved by USM Animal Ethics Committee (Approval Number: USM/ Animal Ethics Approval/ 2013 / (89) (492).

\section{Preparation of aortic ring:}

In this assay, the rat aortic endothelium exposed to a threedimensional matrix containing angiogenic factors switches to a microvascular phenotype generating branching networks of microvessels (Nicosia et al., 1992). The assay was performed according to the standard protocol (Umar et al., 2014) with minor modifications. The animals were sacrificed via cervical dislocation under anaesthesia with $\mathrm{CO}_{2}$. A midline was made into the abdominal and thoracic cavities including splitting of the sternum. Thoracic aortas were excised, rinsed with serum free media. The aorta tissues were cross sectioned into thin rings approximately 1 $\mathrm{mm}$ thickness. Aortic ring sections were then seeded in 48-well plate loaded with serum free M199 supplemented with fibrinogen $(3 \mathrm{mg} / \mathrm{mL})$ and aprotonin $(5 \mu \mathrm{g} / \mathrm{mL}) .10 \mu \mathrm{L}$ of thrombin; prepared at $50 \mathrm{NIH} \mathrm{U/mL} \mathrm{in} 0.15 \mathrm{M} \mathrm{NaCl}$ in $1 \%$ bovine serum albumin was added to each well and was allowed to solidify at $37^{\circ} \mathrm{C}$ in $5 \% \mathrm{CO}_{2}$ for $90 \mathrm{~min}$. The top liquid layer culture medium was prepared by adding the following to M199 basal medium, fetal bovine serum (FBS) at $20 \% \mathrm{v} / \mathrm{v}, \mathrm{L}$-glutamine at $1 \%$, aminocaproic acid at $0.1 \%$, amphotericin $\mathrm{B}$ at $1 \%$ and gentamicin at $0.6 \%$. The $\mathrm{IC}_{50}$ value was determined using serial concentrations $(6.5-100 \mu \mathrm{g} / \mathrm{mL})$ and the plate was incubated at $37{ }^{\circ} \mathrm{C}$ in $5 \% \mathrm{CO}_{2}$ in a humidified incubator. On day four, the top liquid layer culture medium was discarded and changed with fresh medium prepared as previously mentioned with the plant extracts. Culture media was used as a negative control. The work was done in a Class II biosafety cabinet.

The magnitude of blood vessels outgrowth was quantified according to the technique developed by (Nicosia et al., 1997). Briefly, the distance of blood vessels outgrowing from the primary 
tissue ex-plant was measured on day five under the $20 \mathrm{X}$ magnification power of inverted light microscope supplied with Lecia Quin computerized imaging system. The growth distance of at least twenty blood vessels per ring was measured; blood vessels were selected at regular intervals around the rings to reduce the bias. The experiment was performed in triplicates (each replicate containing six rings) and the results were presented as a mean \pm $\mathrm{SD},(\mathrm{n}=6)$. The inhibition of blood vessels formation was calculated.

In vitro assessment of the effect of C5OSEW5050ESA OS Extract on pro and anti-angiogenic growth factor using Luminex Multiplexing Platform

Concentrations of biomarker including vascular endothelial growth factor (VEGF), epidermal growth factor (EGF), basic fibroblast growth factor (b-FGF), transforming growth factor (TGF- $\alpha$ ), tumor necrosis factor (TNF- $\beta$ ) and beta, interleukin-2 (IL-2), interlukin-7 (IL-7), Nerve growth factor (NGF), granulocyte macrophage colony stimulating factor (GM-CSF) and Interferon alpha, beta and gamma (IFNs) were determined in each cell lysates using luminex multiplexing platform. All incubations were performed in the dark at room temperature. Each well of 96well filter plate was pre wetted with $150 \mu \mathrm{L} /$ well of reading buffer for $5 \mathrm{~min}$ at room temperature. The reading buffer was removed from the plates by use of a vacuum filtration. $50 \mu \mathrm{L} /$ well antibodies beads premixed were added to each well. The buffer was removed with vacuum filtration. The antibodies beads were washed with $150 \mu \mathrm{L} /$ well $1 \mathrm{X}$ washing buffer. The washing buffer was removed and the residual buffer was removed by blot the bottom of the filter plate thoroughly with paper towels. The standards, blanks and samples were added (50 $\mu \mathrm{L} /$ well) in duplicate. The filter plate was covered with plate seal, wrapped with aluminium foil and incubated 1 hour on orbital plate shaker (500- $600 \mathrm{rpm})$. The liquid was removed from the plate using vacuum filtration. The plate was washed three times with $150 \mu \mathrm{L} /$ well of washing buffer. The biotinylated detector antibody was added $(25 \mu \mathrm{L})$ to each well and incubated the plate for $30 \mathrm{~min}$ at room temperature on an orbital shaker (500-600 rpm). The solution was removed and the plate was wash three times with $150 \mu \mathrm{L}$ /well of $1 \mathrm{X}$ wash buffer. Streptavidin-PE was added ( $50 \mu \mathrm{L} /$ well) and incubated for $30 \mathrm{~min}$ on a plate shaker (500-600 rpm). The plate was then washed three times with $150 \mu \mathrm{L} /$ well of washing buffer. Finally, $120 \mu \mathrm{L} /$ well of reading buffer was added to each well and the intensity fluorescence was measured and analysed by the Luminex Multiplexing Platform after incubation for $5 \mathrm{~min}$.

Assessment of in vivo anti-angiogenic effect of C5OSEW5050ESA OS Extract using chorioallantoic chick membrane

In vivo anti-angiogenic activity of the extract was evaluated using chick chorioallantoic membrane (CAM) assay (West et al., 2001;
Ribatti, 2008). Five day-old fertilized specific pathogen free eggs were used in the study. The eggs were sterilized by antiseptic solution (70\% alcohol), incubated at $37{ }^{\circ} \mathrm{C}$ and $60-70 \%$ humidity. Albumin $(5-7 \mathrm{~mL})$ was aspirated using a sterilised $18 \mathrm{G}$-needle syringe, the holes was covered with sterilized surgical tape in order to avoid the further albumin flow out or contamination. The eggs were incubated over night at $37{ }^{\circ} \mathrm{C}$ and $60-70 \%$ humidity horizontally to allow the CAM to detach from the eggs shell.

The extract was prepared in $1.2 \%$ agarose discs (50 and 100 $\mu \mathrm{g} / \mathrm{disc})$. Discs containing the vehicle were used as negative control. Then, a small opening with $2-2.5 \mathrm{~cm}$ in diameter on the broad pole was made in the shell and the discs were directly applied onto the CAM at the high density of blood vessels (Özcetin, Aigner, \& Bakowsky, 2013). The square opening was sealed with sterilized surgical tape and the embryo was incubated for $24 \mathrm{~h}$. The CAM was photographed under a dissecting microscope $(n=6)$.

\section{Assessment of in vivo anti-angiogenic effect of C5OSEW5050ESA OS Extract using Matrigel plug assay}

\section{Experimental animals}

Athymic NCR nu/nu nude mice aged 6-8 weeks with a weight of $25 \pm 2 \mathrm{~g}$ were obtained from Taconic Farms Inc., USA. The mice were kept in a specific pathogen free (SPF) cages provided with high efficiency particulate air (HEPA) filter using Animal Transport Unit (Allenton.USA). Mice were provided with sterile food, water and bedding using autoclave (Hirayama-Hiclave, Japan) and housed under a standardized $12 \mathrm{~h}$ light and $12 \mathrm{~h}$ dark cycle at room temperature of $24 \pm 2^{\circ} \mathrm{C}$ and a humidity of $60 \%$. Experimental work was done according to the guidelines of Universiti Sains Malaysia (USM) Animal Ethics Committee (reference number: USM/ Animal Ethics Approval (2 013 / (89) (492).

\section{Establishment of the Subcutaneous Matrigel Plug Assay}

Eighteen male athymic $\mathrm{Nu} / \mathrm{Nu}$ mice were given subcutaneous injections in the right flank with $0.5 \mathrm{ml}$ of Matrigel containing HCT116 tumor cells as angiogenic inducers, using $1 \mathrm{~mL}$ a ice-cold syringe attached to 25 gauge needle. The injection site was press by sterile cotton swab in order to prevent leakage of the cells. After injection, the Matrigel rapidly formed a plug. The animals were divided randomly into three groups of 6 animals. Group 1 and 2 were administered with $100 \mathrm{mg} / \mathrm{kg}$ and $200 \mathrm{mg} / \mathrm{kg}$ C5OSEW5050ESA OS extract, respectively for 7 days, starting from the day of matrigel plug implantation. The third group received distilled water as negative control. On the $7^{\text {th }}$ day, the skin of the mouse was easily pulled back to expose the Matrigel plug. The plug was carefully harvested from the euthanized animal (Kragh et al., 2003) and kept in 10\% formaldehyde.

Quantification of blood vessels was achieved through sectioning and staining with hematoxylin and 
eosin (H\&E) Staining, which stains the basement membrane extract blue and the endothelial cells/vessels red. The number of blood vessels was counted in the treated and untreated section. 6-8 microscopic fields per section were examined at $20 \mathrm{X}$ magnification.

Assay for microvessel density (MVD).

The microvessel density of the embedded matrigel was quantified by immunohistochemistry (IHC) staining using mouse podocalyxin antibodies, which are normally expressed on all vascular endothelial cells (Horvat et al.,1986) according to previously describe method (Birner et al., 2001; Badroon et al., 2020). Briefly, tissues were collected and preserved in $10 \%$ paraformaldehyde. Tissue block was embedded in paraffin and cut at $4 \mu \mathrm{m}$ sections. Prior to IHC staining, the tissue was deparaffinised and rehydrated by processing through graded series of ethanol. The sections were incubated with antigen retrieval in microwave and washed with PBS followed by incubated with Sudan black for $1 \mathrm{hr}$. Subsequently, blocking the section with $5 \%$ BSA for $1 \mathrm{hr}$ and incubated with primary antibodies (anti-mouse podocalyxin) over night at $2^{\circ} \mathrm{C}$ followed by washing with PBS. Sections were incubated with secondary antibody (Alexa-Fluor 488 donkey anti-goat IgG,) for 1 hour at room temperature. The same steps were applied to the negative control sections but without adding the primary antibodies. Sections were washed three times in PBS-T following by mounting with DAPI (Fluorescent mounting medium). Finally, sections were examined using microscope with a $20 \mathrm{X}$ objective.

\section{Result}

HPLC analysis of C5OSEW5050ESA OS Extract HPLC chromatograms of standard markers rosmarinic acid, sinensetin, eupatorin and 3'-hydroxy-5, 6, 7, 4'-tetramethoxyflavone and bioactive markers compounds present in C5OSEW5050ESA OS are shown in figure 1.

C5OSEW5050ESA OS Extract inhibits sprouting of microvessels in rat aortic explants

The C5OSEW5050ESA OS extract activity on angiogenesis were studied further using an ex vivo rat aortic ring assay. As shown in figure $2 \mathrm{~A}$, microvessels out growth developed extensively from the rat aortic in the control when cultured in the medium, whereas, the C5OSEW5050ESA OS extract treated tissue samples has significantly reduced appearance of the microvessels. The antiangiogenic effect of C5OSEW5050ESA OS extract on explants of rat aorta showed significant dose dependent manner $(P<0.05)$, and microvessel growth was almost completely inhibited at $100 \mu \mathrm{g} / \mathrm{mL}$ of C5OSEW5050ESA OS extract (Figure 2 (F). Figure 3 shows a dose dependent anti-angiogenic property of C5OSEW5050ESA OS extract. The $\mathrm{IC}_{50}$ value for C5OSEW5050ESA OS was calculated to be $18.2 \pm 2 \mu \mathrm{g} / \mathrm{mL}$.
C5OSEW5050ESA OS extract inhibits vascular endothelial growth factor pathway in HUVEC Cells

The level of VEGF in treated and untreated HUVECs was examined using luminex multiplexing platform. Data shows that the treatment caused a significant decrease in VEGF content in HUVECs cell compared to control $(16.5 \pm 1.3 \mathrm{pg} / \mathrm{mL})$. The extract shows a dose dependent reduction of VEGF levels (Figure 4).

C5OSEW5050ESA OS inhibits extract epidermal growth factor, basic- fibroblast growth factors pathway on HUVEC Cells

Data shows that the treatments with C5OSEW5050ESA OS extract at different doses causes a significant decrease in EGF expression in HUVECs cells compared to control $(27.8 \pm 3.3 \mathrm{pg} / \mathrm{mL})$. The extract shows a dose dependent reduction of EGF expression levels (Figure $5(\mathrm{~A})$.

Effect of C5OSEW5050ESA OS extract and Imatinib ${ }^{(\mathrm{R})}$ on the level of basic FGF are presented in figure 5 (B). Result shows that the treatment with C5OSEW5050ESA OS extract at 50 and $100 \mu \mathrm{g} / \mathrm{mL}$ significantly reduce level of FGF content in cells at a greater extent when compared to the control.

C5OSEW5050ESA OS extract induce interferon alpha, beta and gamma pathways in HUVECs cells

The activity of C5OSEW5050ESA OS extract and RA on IFNs were investigated by quantifying the level of INFs in endothelial cell lysate using luminex multiplexing platform. The C5OSEW5050ESA OS extract induce IFNs levels in a dose dependent manner (Figure 6). RA also induces the IFNs levels on HUVEC lysate compared to negative control.

\section{C5OSEW5050ESA OS extract inhibits IL-2 \& IL-7 in HUVECs Cells}

Treatment with C5OSEW5050ESA OS at 25, 50 and $100(\mu \mathrm{g} / \mathrm{mL})$ cause significant reduction of IL-2 levels in HUVECs cell compared to negative control as shown in figure 7 (A).

At the same time, the treatment with C5OSEW5050ESA OS extract exhibited a dose dependent reduction of IL-7 levels as revealed in figure 7 (B).

C5OSEW5050ESA OS extract inhibits transforming growth factor alpha and nerve growth factor of HUVECs cells

Figure 8 (A) illustrates the levels of TGF- $\alpha$ in HUVEC cells after treatment with C5OSEW5050ESA OS extract and Imatinib ${ }^{(\mathrm{R})}$ for $24 \mathrm{~h}$. The results show that C5OSEW5050ESA OS extract at 50 and $100 \mu \mathrm{g} / \mathrm{mL}$ and Imatinib ${ }^{(\mathrm{R})}$ at $50 \mu \mathrm{g} / \mathrm{mL}$ reduce the TGF- $\alpha$ levels compared to negative control. Figure 8 (B) demonstrates the effect of C5OSEW5050ESA OS extract and Imatinib ${ }^{(\mathrm{R})}$ on NGF levels. Treatment with C5OSEW5050ESA OS extract for $24 \mathrm{~h}$ shows down regulation of NGF expression levels in HUVECs in a dose dependent manner. At the same time Imatinib ${ }^{(\mathrm{R})}$ at $50 \mu \mathrm{g} / \mathrm{mL}$ significantly reduce the NGF concentration compared to negative control. 

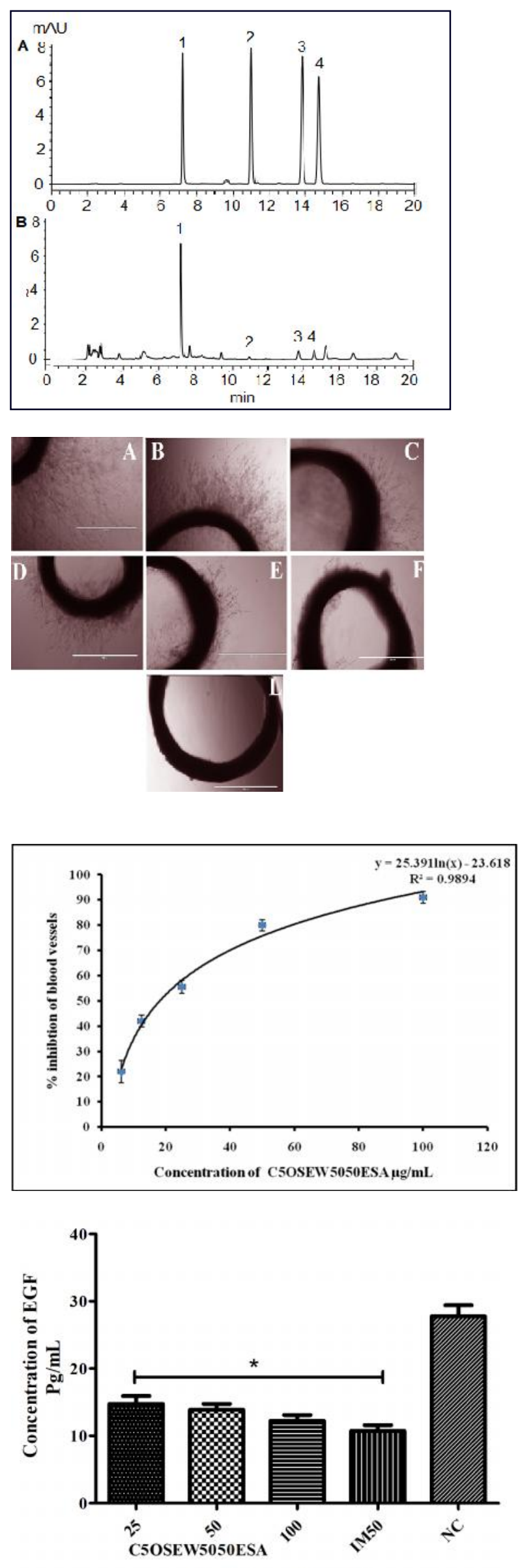

Test Groups $(\mu \mathrm{g} / \mathrm{mL})$
Figure 1: HPLC chromatograms of standard markers, rosmarinic acid, sinensetin, eupatorin and 3'-hydroxy-5, 6, 7, 4'-tetramethoxyflavone present in C5OSEW5050ESA OS Extract. A)HPLC chromatograms of standard markers, rosmarinic acid (1); 3'-hydroxy5,6,7,4'-tetramethoxyflavone (2), sinensetin (3); eupatorin (4) B) Biomarker compounds present in C5OSEW5050ESA OS Extract.

Figure 2: Anti-angiogenic effect of C5OSEW5050ESA OS. Photomicrographs show the inhibition of microvessels outgrowth in the rat's aortic ring. The aortic rings were photographed at 20X magnification, after 5days of treatment with C5OSEW5050ESA OS, (A); Negative control, (B); C5OSEW5050ESA OS $\quad(6.25$ $\mu \mathrm{g} / \mathrm{mL})$, (C); C5OSEW5050ESA OS (12.5 $\mu \mathrm{g} / \mathrm{mL})$, (D): C5OSEW5050ESA OS (25 $\mu \mathrm{g} / \mathrm{mL})$, (E); C5OSEW5050ESA OS (50 $\mathrm{g} / \mathrm{mL}),(\mathrm{F})$; C5OSEW5050ESA OS (100 $\mu \mathrm{g} / \mathrm{mL}),(\mathrm{L})$; Suramin $(100 \mu \mathrm{g} / \mathrm{mL})$. Values are expressed as mean \pm SD, $\mathrm{n}=5$

Figure 3: Dose-dependent inhibitory of C5OSEW5050ESA OS on neovascularisation in the rat aortic tissue explants. Values are expressed as mean \pm $\mathrm{SD}, \mathrm{n}=5$

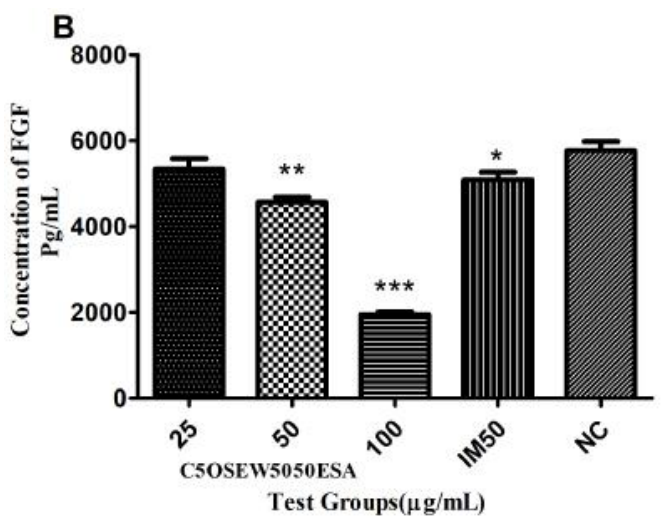

Figure 5A: Inhibitory effects of C5OSEW5050ESA OS extract, Imatinib ${ }^{\circledR}$ (IM50) and negative control (NC) on EGF-Basic . Figure 5B: Effect of FGFbasic expression level in HUVECs cells by C5OSEW5050ESA OS extract, imatinib ${ }^{\circledR}($ IM50) and negative control (NC). The data is presented as mean $\pm \mathrm{SD},{ }^{\star * \star} P<0.001,{ }^{\star *} P<0.01$ and ${ }^{\star} P<0.05$.expression in endothelial cells. 


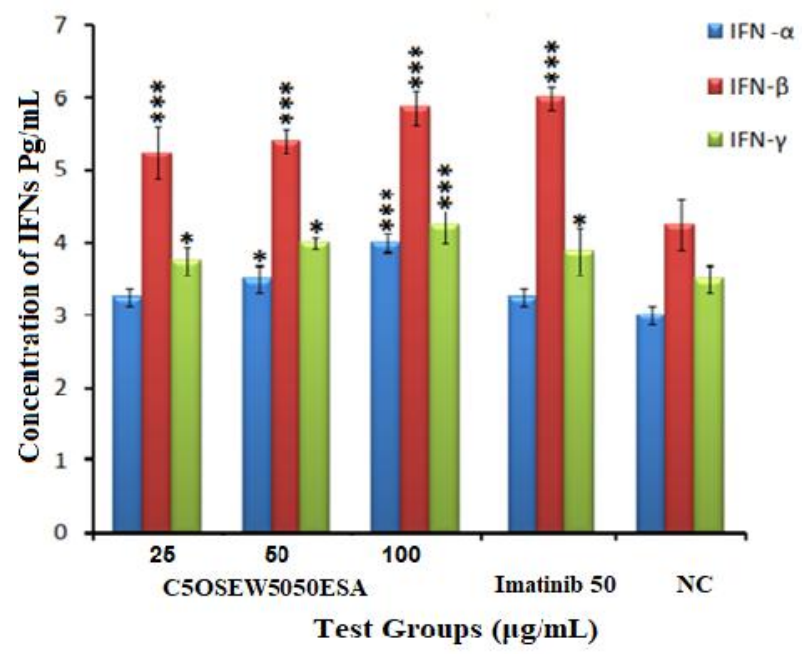

Figure 6: Effect of different doses of C5OSEW5050ESA OS extract, Imatinib ${ }^{\circledR} \quad 50 \mu \mathrm{g} / \mathrm{mLand}$ negative control(NC) on interferon's expression levels in HUVECs cells. Values are represented as mean $\pm S D, n=4$, ${ }^{\star} P<0.05,{ }^{* \star} P<0.01$ and ${ }^{* * *} P<0.001$.

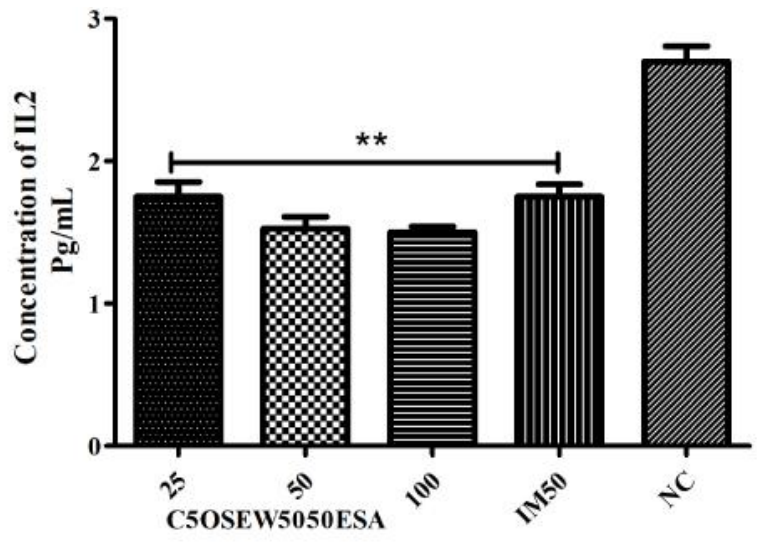

Test Groups $(\mu \mathrm{g} / \mathrm{mL})$

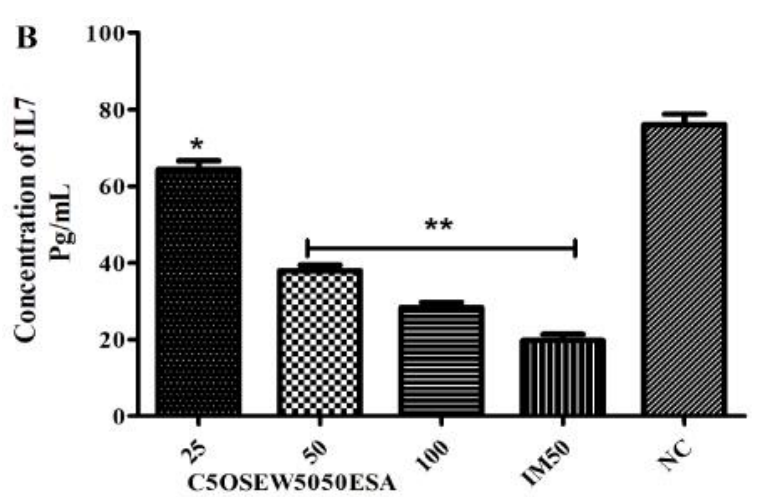

Test Groups $(\mu \mathrm{g} / \mathrm{mL})$

Figure 7: Levels of interleukin-2 (A) and interleukin-7 (B) in HUVECs cells treated with different doses of C5OSEW5050ESA OS extract, imatinib $^{(\mathrm{R})}(\mathrm{IM} 50)$ and negative control (NC). Values are represented as the mean $\pm \mathrm{SD}, \mathrm{n}=4,{ }^{*} p<0.01,{ }^{\star \star} p<0.001$ compared to negative control (NC) group.

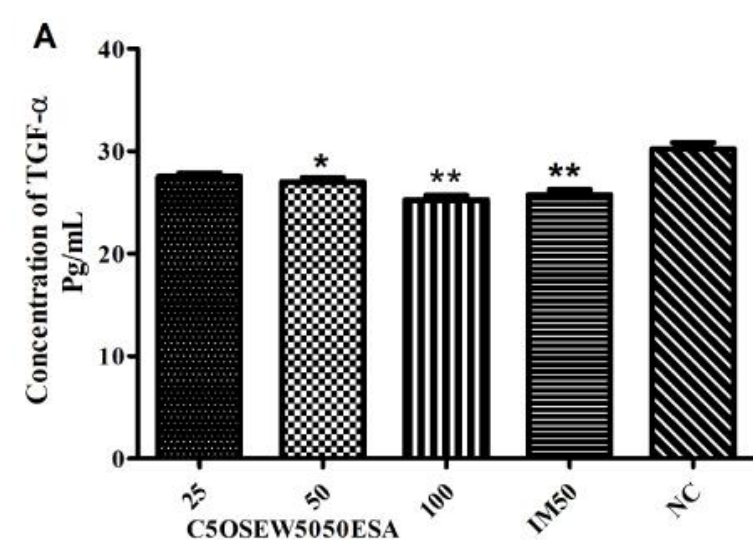

Test Groups $(\mu \mathrm{g} / \mathrm{mL})$

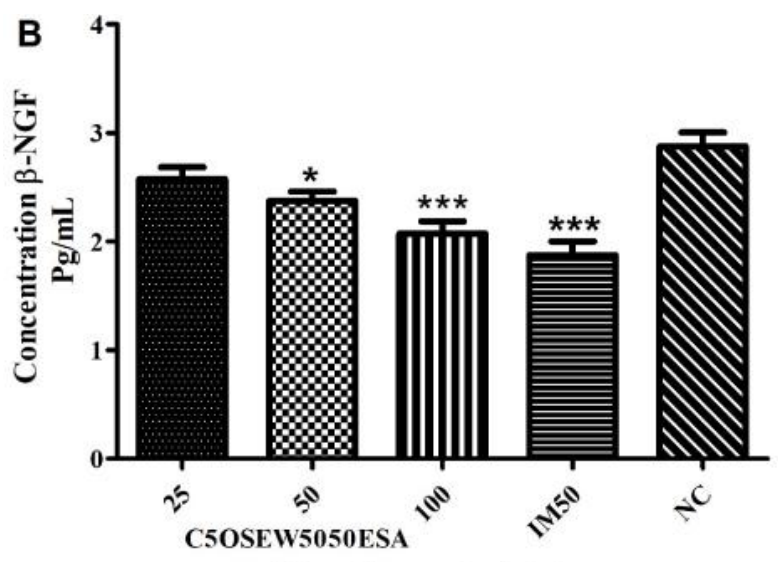

Test Groups $(\mu \mathrm{g} / \mathrm{mL})$

Figure 8: Effect of different doses of C5OSEW5050ESA OS extract, Imatinib ${ }^{(R)}$ (IM50) and negative control (NC) on transfer growth factor $(\mathrm{A})$ and $\beta$-NGF expression in HUVECs cells after $24 \mathrm{~h}$ treatment. Values are represented as mean $\pm \mathrm{SD}, \mathrm{n}=4,{ }^{*} P<$ $0.01,{ }^{\star *} P<0.01,{ }^{\star \star *} P<0.001$ 
C5OSEW5050ESA OS extract induce GM-CSF in HUVECs cells The effect of C5OSEW5050ESA OS extract and Imatinib ${ }^{(\mathrm{R})}$ on GM-CSF is depicted in figure 9. The result shows that only C5OSEW5050ESA OS extract induce GM-CSF expression levels significantly at $100 \mu \mathrm{g} / \mathrm{mL}$ on HUVECs compared to negative control.

\section{Effect of C5OSEW5050ESA OS extract on TNFs in HUVECs} cells

Detection and quantification of the TNF- $\alpha$ and $\beta$ in treated and untreated HUVEC cells were measured using luminex multiplex platform. The result shows that there is no significant effect towards TNF- $\alpha$ or $\beta$ levels in all examined groups compared to the negative control (Figure $10 \mathrm{~A}$ and $\mathrm{B}$ ).

\section{In vivo anti-angiogenic activity of C5OSEW5050ESA OS extract}

In vitro anti-angiogenic assay showed high potency of the C5OSEW5050ESA OS extract in inhibiting the blood vessels formation. To further validate this activity, in vivo studies using chick embryo chorioallantoic membrane (CAM) and mouse matrigel plug assay was carried out.

\section{Effect of C5OSEW5050ESA OS extract on neovascularization in}

\section{Chick Chorioallantoic Membrane assay}

The result in Figure 11 shows that the C5OSEW5050ESA OS extract significantly inhibits neovascularization in CAM assay $(p<0.001)$. The vasculature pattern formed by the blood vessels in CAM test of the control group treated with vehicle (1\% ethanol) was normal. The primary, secondary and tertiary vessels with the dendrites branching pattern are the main characteristics of CAM assay, appears to be well established in negative control group (Figure $11(\mathrm{~A})$ ). In contrast, the treated CAM with 50 and 100 $\mu \mathrm{g} /$ disc of C5OSEW5050ESA OS extract shows distorted vasculature architecture (Figure11 (B\&C)). The quantification of blood vessels in CAM are represented in figure $11(\mathrm{E})$. secondary and tertiary branches of blood vessels (arrow heads). (C); CAM treated with C5OSEW5050ESA OS (100 $\mu \mathrm{g} / \mathrm{disc})$ shows a significant suppression of neovascularization, the treatment caused disruption of main branches of blood vessels (arrow heads), (E); Represents the account of blood vessels in CAM. The photos were captured under dissecting microscope.

Values represented as mean $\pm \mathrm{SD},(n=5),{ }^{*} p<0.001$.

In vivo anti-angiogenic effect of C5OSEW5050ESA OS extract on Matrigel plug assay in mice

Morphology of the excised matrigel plug shows significant reduction in blood vessels density in the plug harvested from animals treated with C5OSEW5050ESA OS extract at 100 and 200 $\mathrm{mg} / \mathrm{kg}$ compared to the plug of negative control group (Figure 12 (A, B and C). In addition, plug sections from C5OSEW5050ESA OS extract treated with $100,200 \mathrm{mg} / \mathrm{kg}$ and negative control mice were stained with hematoxylin/eosin stain and examined for qualification of the blood vessels. The histology of plug from the control mice shows abundance blood vessels as indicated by the arrows, while the histology of plug from treated animals with C5OSEW5050ESA OS extract shows significantly reduced blood vessels (Figure 12 (D, E, F)).

The most remarkable change observed in plug histology was that the treatment with C5OSEW5050ESA OS extract caused reduction in the plug vascular density. The treatment with C5OSEW5050ESA OS extract resulted in a significant decline in blood vessel formation compared to the negative control group $(p<0.001)$. The percent inhibition of the blood vessel counting in the plug is $71.9 \pm 4$ and $85.4 \pm 3 \%$ at 100 and $200 \mathrm{mg} / \mathrm{kg}$, respectively. The mean quantification of blood vessels in the matrigel plug of mice treated with 100 and 200 of C5OSEW5050ESA OS extract was $123 \pm 15.3$ and $62 \pm 8.2$, respectively (Figure 12 ( II and III). While, the average of blood vessels in the negative control was $434 \pm 34(P<0.001)$ (Figure 12 (I).

\section{Discussion}

Angiogenesis is a multistep process which is initiated through stimulation of endothelial cells by growth factors, followed by degradation of basement membrane, detachment of endothelial cells from adhesion proteins, endothelial cell migration and proliferation into the perivascular spaces (Folkman and Shing, 1992; Yance and Sagar, 2006). Modulating angiogenic signals has therapeutic value in angiogenic-related diseases such as arthritis, diabetic and most notably cancer (Ledermann, 1999). In this study, a proprietary clinical trial extract of $O$. stamineus code named C5OSEW5050ESA OS was evaluated for its antiangiogenic property. The botanical drug formulation of C5OSEW5050ESA OS, Nuvastatic, has recently completed a phase $2 / 3$ clinical studies for cancer fatigue in stage 1-4 cancer patients with solid tumors who were receiving chemotherapy and radiotherapy (ClinicalTrials.gov Identifier: NCT04546607). Rosmarinic acid is one of the main active marker compounds of C50SEW5050ESA which range between $6-8 \% \mathrm{w} / \mathrm{w}$ followed by eupatorin $0.2 \%$ and sinensetin $0.07 \% \mathrm{w} / \mathrm{w}$. The C5EOS5050ESA was found to significantly inhibit angiogenesis in vitro and in vivo. The compound inhibits neovascularisation of isolated rat aortic ring and caused significant reduction in new blood vessel formation as observed in the CAM assay as well as the mouse matrigel plug studies. C5OS5050ESA was found to be noncytotoxic towards endothelial cells and disrupted the formation of tube-like endothelial structures.

The results of this study show strong inhibition of neovascularisation supporting previous findings on methanol leaf extract of the Orthosiphon stamineus species (Sahib et al., 2009). The strong inhibition of C5EOS5050ESA may be attributable to 


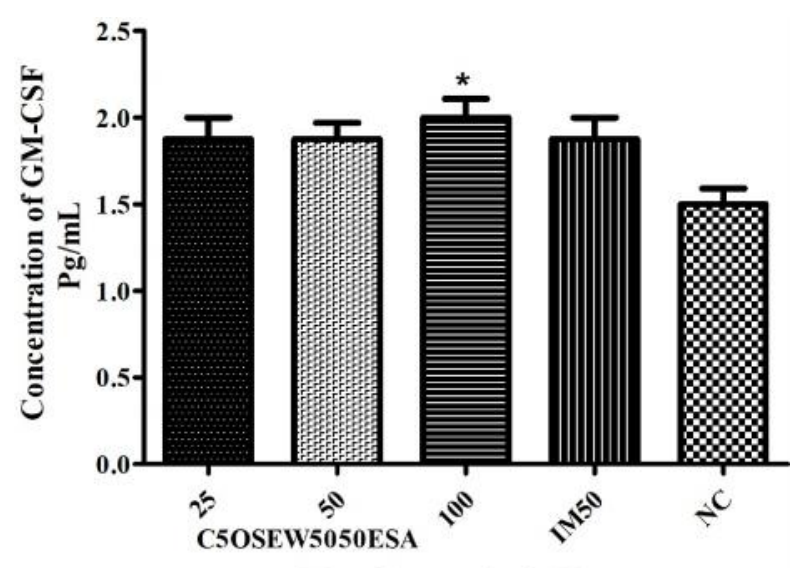

Test Groups $(\mu \mathrm{g} / \mathrm{mL})$
Figure 9: Effect of different doses of C5OSEW5050ESA OS extract, Imatinib ${ }^{(R)}$ (IM50) and negative control (NC) on GM-CSF expression in HUVECs. Values are represented as mean $\pm \mathrm{SD}, \mathrm{n}=4,{ }^{*} P<0.01$.

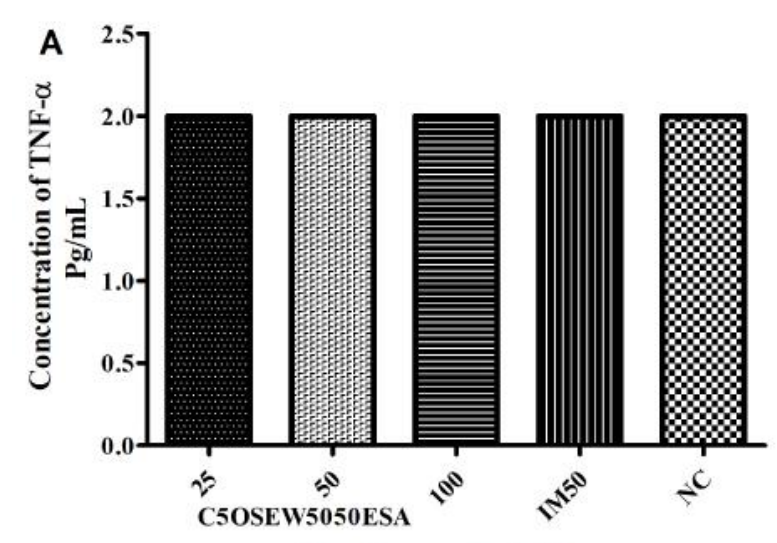

Test Groups $(\mu \mathrm{g} / \mathrm{mL})$

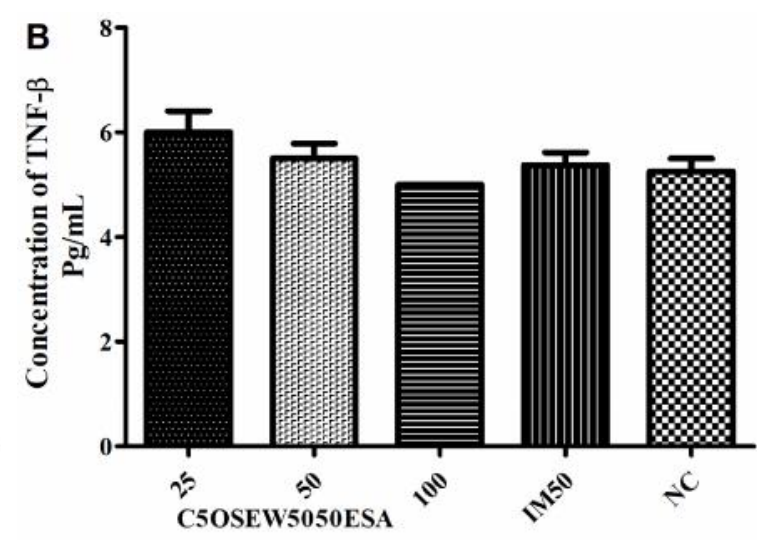

Test Groups $(\mu \mathrm{g} / \mathrm{mL})$

Figure 10: Effect of different doses of C5OSEW5050ESA OS extract, Imatinib ${ }^{(R)}$ (IM50) and negative control (NC) on TNF $\boldsymbol{\alpha}$ and TNF $\beta$ expression in Human Umbilical Vein Endothelial Cells, respectively. Values are represented as mean \pm SD, $n=4$. $P$ $>0.5)$
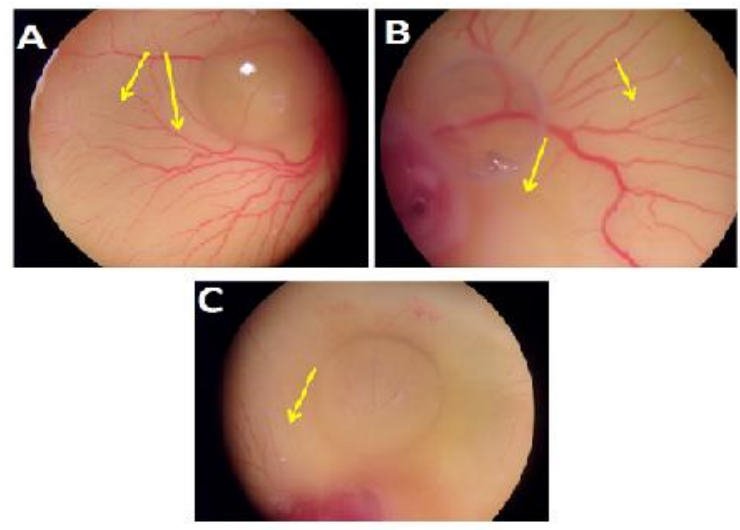

$\mathbf{E}$

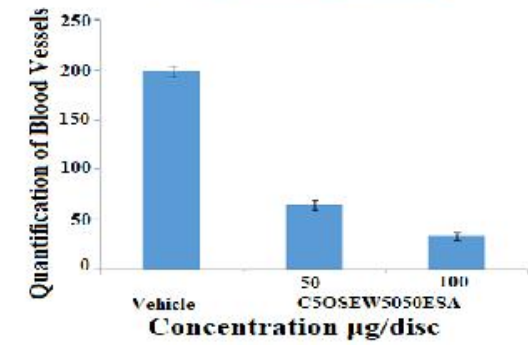

Figure 11: Inhibitory effect of different doses of C5OSEW5050ESA OS extract and negative control vehicle on neovascularization in chorioallantoic membrane of chick embryo, (A); CAM treated with vehicle as a negative control which shows enormous neovasularization with primary, secondary and tertiary branches of blood vessels (arrows), (B); CAM treated with C5OSEW5050ESA OS $(50 \mu \mathrm{g} / \mathrm{ml})$ shows inhibition of secondary and tertiary branches of blood vessels (arrow heads). (C); CAM treated with C5OSEW5050ESA OS (100 $\mathrm{\mu g} /$ disc) shows a significant suppression of neovascularization, the treatment caused disruption of main branches of blood vessels (arrow heads), (E); Represents the account of blood vessels in CAM. The photos were captured under dissecting microscope. Values represented as mean $\pm \mathrm{SD},(n=5),{ }^{\star} p<0.001$. 

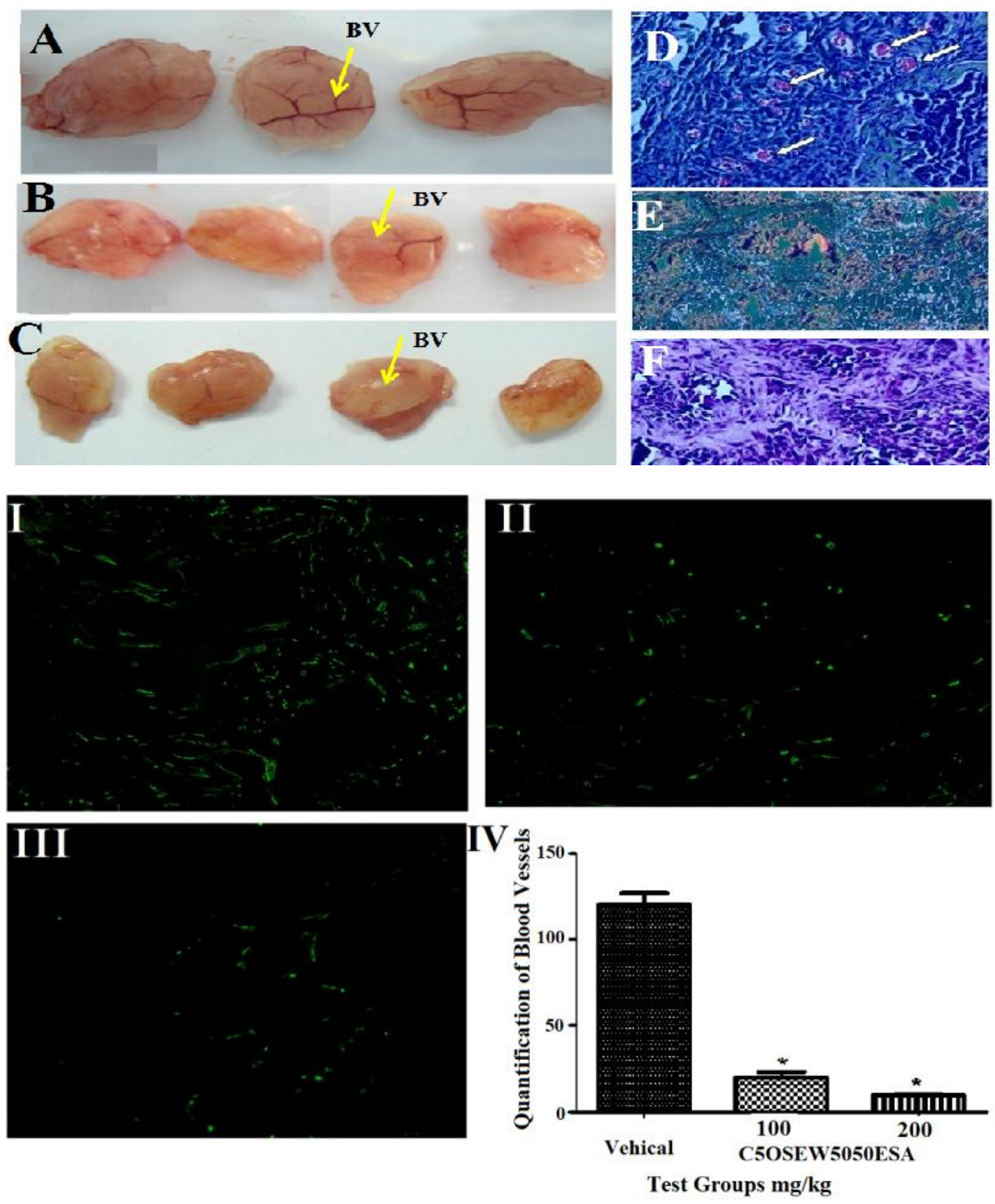

Figure12: Anti-angiogenic effects of C5OSEW5050ESA OS extract on matrigel plug (A); Morphological features of matrigel plug harvested from negative control animal. (B); Morphological features of matrigel plug harvested from animal treated with $100 \mathrm{mg} / \mathrm{kg}$, (C); Morphological features of matrigel plug harvested from animal treated with $200 \mathrm{mg} / \mathrm{kg}$, (D); Histology (H \& E stained) matrigel plug sections of negative control group containing abundance of blood vessels (BV) indicated by white arrows: (E); Matrigel plug section of C5OSEW5050ESA OS extract (100 mg/kg), (F); the matrigel plug section of C5OSEW5050ESA OS $(200 \mathrm{mg} / \mathrm{kg})$, (l); Blood vessels of matrigel section for negative control group stained by immunohistochemistry, (II); Blood vessels of matrigel section treated with $100 \mathrm{mg} / \mathrm{kg}$ stained by immunohistochemistry, (III); Blood vessels of matrigel section treated with $200 \mathrm{mg} / \mathrm{kg}$ staining by immunohistochemistry, (IV); Blood vessels account of vehicle and treated groups. Photos were taken at magnification of $20 \mathrm{X}$. The blood vessels were counted in 6 microscopic fields/ slide. Values represented as mean : $\mathrm{SD},(n=6),{ }^{*} p<0.001$. 
the presence of polyphenolic and flavonoid compounds such as RA, EUP, SIN, BA and TMF (Siddiqui et al., 2009; Al-Suede et al.,2014). Luminex multiplex assay on HUVECS cells exposed to C5EOS5050ESA reveal that the compound significantly inhibits cellular VEGF-A (see Figure 3). It also inhibits EGF, IL-2 IL-7, FGF-Basic, TGF- $\alpha$, TNF- $\beta$ and $\beta$-Nerve growth factor (see Figure $4,6,7$ and 9). A novel significant finding on C5EOS5050ESA is its ability to stimulate GM-CSF (Figure 8) and Interferon $\beta$, $\alpha$ and $\gamma$ (Figure 5).

It is known that several cytokines can work as upregulators of angiogenesis by promoting blood vessel formation in human cancer including VEGF (Achen and Stacker, 1998), EGF, a-FGF and b-FGF (Turner and Grose, 2010), TNF-a (Hagemann et al., 2004), TGF- $\alpha$ and TGF- $\beta$ (Ferrari et al., 2009), IL-2 \& 7 (Karamysheva, 2008). Our finding shows that C5OSEW5050ESA OS inhibits the pro-angiogenic factors such as EGF, FGF-b, VEGF, TGF- $\beta$ and IL- 2 \& 7 in a dose dependent manner.

IL-2 is an important growth factor that has been shown to promote angiogenesis in both in vivo and in vitro. This is mediated by phosphorylation of Akt in HUVECs which increases the level of ROS and synthesis and secretion of VEGF (Bae et al., 2008; Al-Salahi et al., 2013). In addition, IL-2 gene expression can be induced by IL-7 via regulating activator protein (AP-1)-DNA binding activities in activated human $\mathrm{T}$ lymphocytes (Gringhuis et al., 1997). Moreover, IL-7 induces lymphangiogenic, motility and migration of endothelial cells via up regulated VEGF-D expression at both mRNA and protein levels in vitro (Al-Rawi et al., 2005).

In addition, NGF is mitogenic to keratinocytes and play critical role in numerous key processes in wound healing such as angiogenesis, reepithelialization, and reinervation. It has essential effect in the initiation and maintenance of inflammation in many organs; in addition, it also has activity on the central nervous system and formation of granulation tissue

In the present work, the anti-angiogenic effect of C5OSEW5050ESA OS could be due to targeting pro-angiogenic factors such as IL-2, IL-7, NGF and TGF signalling pathways or by inducing the angiogenic inhibition factors such as IFN $\beta, \alpha, \gamma$ and GM-CSF. These effects of C5OSEW5050ESA may be attributed to its anti-oxidant property and presence of phytonutrients such as polymethoxylated flavonoids, polyphenolic contents, caffeic acid derivatives and terpenes, particularly eupatorin, sinensetin, rosmarinic acid, 3'-hydroxy-5,6, 7,4'- tetramethoxyflavone and betulinic acid (Tabana et al 2016, Losso, 2003). These series of compounds possess their own unique anti-angiogenic property which may afford a powerful combination in preventing or treating tumor development.

The outcome of this study is in line with the finding of previous study which reported that the anti-angiogenic and antitumor efficacy of $50 \%$ ethanol extract of Orthosiphon stamineus could be mediated via inhibition of VEGF signaling pathway (Ahamed et al., 2012). It was concluded that the OS extract was shown to exert dual activities; it inhibits the manufacture of essential proangiogenic molecules from cancer cells and suppresses the phosphorylation of VEGFR-2 in HUVECs (Ahamed et al., 2012).

This study also reveals the strong immune modulatory property of C5OSEW5050ESA OS by causing upregulation of IFN $\beta, \alpha, \gamma$ and GM-CSF and at the same time inhibiting IL-2, IL-7, $\beta$ NGF and TGF- $\alpha$. IFNs belong to the large class of cytokine family that act as mediators between cells to trigger the protective defences of the immune system that help eradicate pathogens.( Parkin \&Cohen 2001). Interferons regulate antitumor, apoptotic, and cellular immune responses, and is an established angiogenesis inhibitor. Angiogenesis is stimulated by VEGF and antagonized by type 1 interferons, including IFN- $\alpha / \beta$. IFNs inhibit secretion of such angiogenic factors as basic fibroblast growth factor from tumor cells. IFNs also activate immune cells, such as natural killer cells and macrophages and they increase host defenses by upregulating antigen presentation by upregulating the expression of major histocompatibility complex (MHC) antigens. Cytokines, such as IL2, TNF and colony-stimulating factor, can also cause an increase in interferon production. IL7 on the other hand is required for $\mathrm{T}$-cell development as well as for the survival and homeostasis of mature T-cells. IL-7 plays important role in at all stages of T-cell development and maintenance, it has been used in clinical trials as an immunotherapeutic agent to treat cancer ( Haller et al., 2007).

Flavonoids are polyphenolic compounds that are abundant in nature and are categorised, according to chemical structure. The flavonoids have potential beneficial effects on human health. Many works have shown that flavonoids contain anti-inflammatory, anti-angiogenic, antitumor, anti-allergic, antiviral and anti-oxidant activities (Wu et al., 2012). The capacity of flavonoid to act as anti-oxidant depends upon their molecular structure and chemical properties. Hydroxyl group's position and other features in the chemical structure of flavonoids are important for their anti-oxidant and free radical scavenging activities (Kumar \& Pandey, 2013). Previous studies demonstrated the role of terpenoids, flavonoids and the isolated primary metabolites such as polysaccharides, proteins and saponins in inhibition of angiogenesis (Sahib et al., 2009).

Akowuah et al. reported that the anti-oxidant activity occurred as a result of the presence of phenolic and pentacyclic triterpenes such as ursolic acid, oleanolic acid and betulinic acid (Akowuah et al., 2005). Furthermore, many staminane-type diterpenes present in O. stamineus contains hydroxyl, carboxylate and terminal methylene group which have hydrogen-donating ability and may possibly contribute to the free radical scavenging activity (Tezuka 
et al., 2000). Reducing property of these compounds is responsible for their main effects. The C5OSEW5050ESA OS contains high amounts of primary and secondary metabolites (flavonoids, triterpenoids and phenolic component) which may have contributed towards its anti-angiogenic and immunomodulatory properties.

\section{Conclusion}

The present study shows that the C5OSEW5050ESA OS extract significantly inhibits angiogenesis and affects overall process of neovascularisation of endothelial cells through inhibition of cellular adhesion molecules, cell migration, invasion, and extracellular proteolysis. The study also highlights the immunomodulatory property of C5OSEW5050ESA OS by stimulating IFN $\beta, \alpha, \gamma$ and GM-CSF and at the same time inhibiting IL-2, IL-7, $\beta$-NGF and TGF- $\alpha$. This result of this study highlights the potential benefits of C5OSEW5050ESA OS in cancer therapy.

\section{Author Contributions}

FSRA, MBKA, ASAM have designed the experiments. FSRA and SMSA have conducted the experiments. FSRA, CEO and AMSA have drafted the manuscript. All the authors read and approved the final manuscript.

\section{Acknowledgment}

This work was funded by the Malaysian Ministry of Agriculture, Malaysia, under NRGS grant no. 304/PFARMASI/650583/K123. We would like to thank School of Pharmaceuticals Sciences, Universiti Sains Malaysia for providing access to some of their facilities.

\section{Competing financial interests}

Mohamed B. Khadeer Ahamed, Aman S. Abdul Majid, Amin Malik Shah Abdul Majid have commercial interest in C5OSEW5050ESA OS and Nuvastatic. All other authors declare no competing financial interests.

\section{References}

Achen, M. G., \& Stacker, S. A. (1998). The vascular endothelial growth factor family; proteins which guide the development of the vasculature. International Journal of Experimental Pathology, 79, 255-65.

https://doi.org/10.1046/j.1365-2613.1998.700404.x

Ahamed, M. B., Aisha, A. F., Nassar, Z. D., Siddiqui, J. M., Ismail, Z., Omari, S. M., et al. (2012). Cat's whiskers tea (Orthosiphon stamineus) extract inhibits growth of colon tumor in nude mice and angiogenesis in endothelial cells via suppressing VEGFR phosphorylation. Nutrition and Cancer, 64(1), 89-99

https://doi.org/10.1080/01635581.2012.630160
Aisha, A. F. A., Majid, A. M. S. A., \& Ismail, Z. (2014). Preparation and characterization of nano liposomes of Orthosiphon stamineus ethanolic extract in soybean phospholipids. BMC Biotechnology, 14, 23-23.

https://doi.org/10.1186/1472-6750-14-23

Akowuah, G. A., Zhari, I., Norhayati, I., Sadikun, A., \& Khamsah, S. M. (2004). Sinensetin, eupatorin, 3'-hydroxy-5, 6, 7, 4'-tetramethoxyflavone and rosmarinic acid contents and antioxidative effect of Orthosiphon stamineus from Malaysia. Food Chemistry, 87(4), 559-566.

https://doi.org/10.1016/j.foodchem.2004.01.008

Akowuah, G., Ismail, Z., Norhayati, I., \& Sadikun, A. (2005). The effects of different extraction solvents of varying polarities on polyphenols of Orthosiphon stamineus and evaluation of the free radical-scavenging activity. Food chemistry, 93, 311-317.

https://doi.org/10.1016/j.foodchem.2004.09.028

Al-Rawi, M. A., Watkins, G., Mansel, R. E., \& Jiang, W. G. (2005). The effects of interleukin-7 on the lymphangiogenic properties of human endothelial cells. International Journal of Oncology, 27, 721-30.

Al-Salahi, O. S. A., Kit Lam, C., Majid, A. M. S. A., Al-Suede, F. S. R., Mohammed Saghir, S. A., Abdullah, W. Z., Ahamed, M. B. K., \& Yusoff, N. M.( 2013). Anti-angiogenic quassinoid-rich fraction from Eurycoma Iongifolia modulates endothelial cell function. Microvascular Research, 90, 30-39.

https://doi.org/10.1016/j.mvr.2013.07.007

Alshawsh, M. A., Abdulla, M. A., Ismail, S., \& Amin, Z. A.( 2011). Hepatoprotective Effects of Orthosiphon stamineus Extract on Thioacetamide-Induced Liver Cirrhosis in Rats. Evidence-Based Complementary and Alternative Medicine, 2011, 6.

https://doi.org/10.1155/2011/103039

Al-Suede, F. S. R., Elham, F., Mohamed B. Khadeer Ahamed, Z. Ismail, Majid, A. S. A., \& A. M. S. Abdul Majid. (2014a). Marked antitumor activity of cat's whiskers tea (Orthosiphon stamineus) extract in orthotopic model of human colon tumor in nude mice. Journal of Biochemical Technology, 3(5), S 170-176.

Al-Suede, F. S R., Majid, A. S. A., Ismail, Z., Kadir, M., \& Majid, A. M. S. A. (2013). Abstract B87: Antiangiogenic and antimetastatic activities of cat's whiskers tea (Orthosiphon stamineus) extract against colon cancer cell line. Cancer Research, 73(3 Supplement), B87-B87.

https://doi.org/10.1158/1538-7445.TIM2013-B87

Al-Suede, F. S. R., Khadeer Ahamed, M. B., Abdul Majid, A. S., Baharetha, H. M., Hassan, L. E., Kadir, M. O. A., ... \& Abdul Majid, A. (2014). Optimization of cat's whiskers tea (orthosiphon stamineus) using supercritical carbon dioxide and selective chemotherapeutic potential against prostate cancer cells. Evidence-Based Complementary and Alternative Medicine, 2014b.

https://doi.org/10.1155/2014/396016 
Badroon, N., Abdul Majid, N., Al-Suede, F. S. R., Nazari V, M., Giribabu, N., Abdul Majid, A. M. S., \& Alshawsh, M. A. (2020). Cardamonin Exerts Antitumor Effect on Human Hepatocellular Carcinoma Xenografts in Athymic Nude Mice through Inhibiting NF-к $\beta$ Pathway. Biomedicines, 8(12), 586

https://doi.org/10.3390/biomedicines8120586

Bae, J., Park, D., Lee, Y. S., \& Jeoung, D. (2008). Interleukin-2 promotes angiogenesis by activation of Akt and increase of ROS. Journal of microbiology and biotechnology, 18, 377-382.

Birner, P., Obermair, A., Schindl, M., Kowalski, H., Breitenecker, G., \& Oberhuber, G. (2001). Selective immunohistochemical staining of blood and lymphatic vessels reveals independent prognostic influence of blood and lymphatic vessel invasion in early-stage cervical cancer. Clin Cancer Res, 7(1), 93-97.

Eubank, T. D., Roberts, R. D., Khan, M., Curry, J. M., Nuovo, G. J., Kuppusamy, P., \& Marsh, C. B. (2009). Gm-csf inhibits breast cancer growth and metastasis.

Ferrara, N. (2001). Role of vascular endothelial growth factor in regulation of physiological angiogenesis. American journal of physiology Cell physiology, 280, C1358-66. https://doi.org/10.1152/ajpcell.2001.280.6.C1358

Ferrari, G., Cook, B. D., Terushkin, V., Pintucci, G., \& Mignatti, P. (2009). Transforming Growth Factor-Beta 1 (TGF-B1) Induces Angiogenesis Through Vascular Endothelial Growth Factor (VEGF)-Mediated Apoptosis. Journal of cellular physiology, 219, 449-458.

https://doi.org/10.1002/jcp.21706

Folkman, J., \& Shing, Y. (1992). Angiogenesis. Journal of Biological Chemistry, 267, 1093110934.

https://doi.org/10.1016/S0021-9258(19)49853-0

Gringhuis, S. I., de Leij, L. F., Verschuren, E. W., Borger, P., \& Vellenga, E. (1997) Interleukin-7 upregulates the interleukin-2-gene expression in activated human T lymphocytes at the transcriptional level by enhancing the DNA binding activities of both nuclear factor of activated $T$ cells and activator protein-1. Blood, 90, 2690-700.

https://doi.org/10.1182/blood.V90.7.2690

Hagemann, T., Robinson, S. C., Schulz, M., Trumper, L., Balkwill, F. R. \& Binder, C. (2004) Enhanced invasiveness of breast cancer cell lines upon co-cultivation with macrophages is due to TNF-alpha dependent up-regulation of matrix metalloproteases. Carcinogenesis, 25, 1543.

https://doi.org/10.1093/carcin/bgh146

Haller, O., Kochs, G., \& Weber, F. (2007). Interferon, Mx, and viral countermeasures. Cytokine \& growth factor reviews, 18(5-6), 425-433.

https://doi.org/10.1016/j.cytogfr.2007.06.001

https://doi.org/10.25163/angiotherapy.51211411913130321
Horvat, R., Hovorka, A., Dekan, G., Poczewski, H., \& Kerjaschki, D. (1986). Endothelial cell membranes contain podocalyxin--the major sialoprotein of visceral glomerular epithelial cells. J Cell Biol, 102(2), 484-491.

https://doi.org/10.1083/jcb.102.2.484

Hussain, K., Ismail, Z., Sadikun, A., Shah, A. M. A. M., Latif, A., \& Hashmi, F. K. (2012). Antiangiogenic Activity and Bioassay-guided Isolation of Aqueous Extract of Orthosiphon stamineus. Journal of the Chinese Chemical Society, 59(9), 11371143.

https://doi.org/10.1002/jccs.201100753

Karamysheva, A. F. (2008). Mechanisms of angiogenesis. Biochemistry (Moscow), 73, 75162

https://doi.org/10.1134/S0006297908070031

Kottakis, F., Polytarchou, C., Foltopoulou, P., Sanidas, I., Kampranis, S. C., \& Tsichlis, P. N. (2011). FGF-2 regulates cell proliferation, migration, and angiogenesis through an NDY1/KDM2B-miR-101-EZH2 pathway. Molecular Cell, 43, 285-98

https://doi.org/10.1016/j.molcel.2011.06.020

Kragh, M., Hjarnaa, P., Bramm, E., Kristjansen, P., Rygaard, J., \& \& Binderup, L. (2003). In vivo chamber angiogenesis assay: An optimized Matrigel plug assay for fast assessment of anti-angiogenic activity. International Journal of Oncology, 22(2), 305-311.

https://doi.org/10.3892/ijo.22.2.305

Ledermann, J. A. (1999). Antiangiogenic Agents in Cancer Therapy. Journal of the Royal Society of Medicine, 92, 603-603.

https://doi.org/10.1177/014107689909201122

Losso, J. N. (2003). Targeting excessive angiogenesis with functional foods and nutraceuticals. Trends in Food Science \& Technology, 14, 455-468.

https://doi.org/10.1016/S0924-2244(03)00156-0

Mohamed, E. A. H., Yam, M. F., Ang, L. F., Mohamed, A. J., \& Asmawi, M. Z. (2013). Antidiabetic Properties and Mechanism of Action of Orthosiphon stamineus Benth Bioactive Sub-fraction in Streptozotocin-induced Diabetic Rats. Journal of Acupuncture and Meridian Studies, 6, 31-40.

https://doi.org/10.1016/j.jams.2013.01.005

Nicosia, R. F., Bonanno, E., \& Villaschi, S. (1992). Large-vessel endothelium switches to a microvascular phenotype during angiogenesis in collagen gel culture of rat aorta. Atherosclerosis, 95, 191-199.

https://doi.org/10.1016/0021-9150(92)90022-9

Nicosia, R. F., Lin, Y. J., Hazelton, D., \& Qian, X. (1997). Endogenous regulation of angiogenesis in the rat aorta model. Role of vascular endothelial growth factor. American Journal of Pathology, 151, 1379-86. 
O'Reilly, M. S., Boehm, T., Shing, Y., Fukai, N., Vasios, G., Lane, W. S., Flynn, E., Birkhead, J. R., Olsen, B. R., \& Folkman, J. (1997). Endostatin: An Endogenous Inhibitor of Angiogenesis and Tumor Growth. Cell, 88, 277-

https://doi.org/10.1016/S0092-8674(00)81848-6

Özcetin, A., Aigner, A., \& Bakowsky, U. (2013). A chorioallantoic membrane model for the determination of anti-angiogenic effects of imatinib. European Journal of Pharmaceutics and Biopharmaceutics, 85(3 PART A), 711-715.

https://doi.org/10.1016/j.ejpb.2013.07.010

Parkin, J., \& Cohen, B. (2001). An overview of the immune system. The Lancet, 357(9270), $1777-1789$.

https://doi.org/10.1016/S0140-6736(00)04904-7

Ribatti, D. (2008). Chick embryo chorioallantoic membrane as a useful tool to study angiogenesis. International Review of Cell And Molecular Biology, 270, 181224.

https://doi.org/10.1016/S1937-6448(08)01405-6

Sagar, S. M., Yance, D., \& Wong, R. K. (2006). Natural health products that inhibit angiogenesis: a potential source for investigational new agents to treat cancer Part 1. Current Oncology, 13, 14-26.

https://doi.org/10.3747/co.v13i1.77

Saidan, N. H., Aisha, A. F., Hamil, M. S. R., Majid, A. M. S. A., \& Ismail, Z. (2015a). A nove reverse phase high-performance liquid chromatography method for standardization of Orthosiphon stamineus leaf extracts. Pharmacognosy research, $7(1), 23$.

https://doi.org/10.4103/0974-8490.147195

Tabana, Y. M., Al-Suede, F. S. R., Ahamed, M. B. K., Dahham, S. S., Hassan, L. E. A., Khalilpour, S., \& Majid, A. M. S. A. (2016). Cat's whiskers (Orthosiphon stamineus) tea modulates arthritis pathogenesis via the angiogenesis and inflammatory cascade. BMC complementary and alternative medicine, 16(1), 480

https://doi.org/10.1186/s12906-016-1467-4

Turner, N., \& Grose, R. (2010). Fibroblast growth factor signalling: from development to cancer. Nature Reviews Cancer, 10, 116-129.

https://doi.org/10.1038/nrc2780

Umar, M. I., Asmawi, M. Z., Sadikun, A., Majid, A. M., Al-Suede, F. S., Hassan, L. E., et al. (2014). Ethyl-p-methoxycinnamate isolated from Kaempferia galanga inhibits inflammation by suppressing interleukin-1, tumor necrosis factor-alpha, and angiogenesis by blocking endothelial functions. Clinics (Sao Paulo), 69(2), 134 144.

https://doi.org/10.6061/clinics/2014(02)10

West, D. C., Thompson, W. D., Sells, P. G., \& Burbridge, M. F. (2001). Angiogenesis assays using chick chorioallantoic membrane. Methods in Molecular Medicine, 46, 107-29.

https://doi.org/10.1385/1-59259-143-4:107

Wu, W. B., Hung, D. K., Chang, F. W., Ong, E. T., \& Chen, B. H. (2012). Anti-inflammatory and anti-angiogenic effects of flavonoids isolated from Lycium barbarum Linnaeus on human umbilical vein endothelial cells. Food Function, 3, 106881.

https://doi.org/10.1039/c2fo30051f

Yance, D. R., \& Sagar, S. M. (2006). Targeting angiogenesis with integrative cancer therapies. Integrative Cancer Therapies, 5(1), 9-29.

https://doi.org/10.1177/1534735405285562

Submit your next manuscript to Journal of Angiotherapy published by EMAN Research

- Convenient online submission

- Thorough peer review

- No space constraints or color figure charges

- Immediate publication on acceptance

- Inclusion in Australian National Libraray and Google Scholar

- $\quad$ Both Open (80-100\% subsidized APC by ER) \& non-open access option

Submit your manuscript at

https://publishing.emanresearch.org 